\title{
GEO BIG DATA AND DIGITAL AUGMENTATION FOR ACCELERATING AGROECOLOGICAL INTENSIFICATION IN DRYLANDS
}

\author{
C. M. Biradar ${ }^{*}$, S. Ghosh ${ }^{1}$, F. Löw ${ }^{1}$, R. Singh ${ }^{2}$, P. Chandna ${ }^{3}$, A. Sarker ${ }^{1}$, R.N. Sahoo ${ }^{4}$, N. Swain ${ }^{1}$, G. Choudhury ${ }^{1}$, S. Agrawal ${ }^{1}$, N

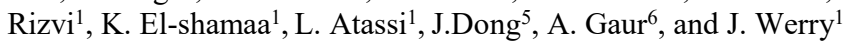 \\ ${ }^{1}$ International Center for Agricultural Research in Dry Areas (ICARDA), Cairo, Egypt - c.biradar@cgiar.org \\ ${ }^{2}$ World Agroforestry Center (ICRAF), New Delhi, India - r.singh@ cgiar.org \\ ${ }^{3}$ International Rice Research Institute (IRRI), New Delhi, India - p.k.chandna@cgiar.org \\ ${ }^{4}$ Indian Agricultural Research Institute (IARI), ICAR, New Delhi, India - rabi.sahoo@icar.gov.in \\ ${ }^{5}$ Institute of Geographic Sciences and Natural Resources Research (IGSNNR) - dongjw@igsnrr.ac.cn \\ ${ }^{6}$ The World Bank Group, New Delhi, India - agaur@worldbank.org
}

Commission III, WG III/10

KEY WORDS: Earth Observation, Digital Augmentation, Big Data, GeoAgro, Agroecology, Rice-Fallows, Intensification, Pulses

\begin{abstract}
:
Integrated system approach becomes key pillar for sustainable intensification of agri-food systems while ensuring ecological functions under changing climate, diet and demography. The digitization of the agroecosystems become most essential entry point for any sustainable developmental entities whether it is plant genetics for breeding better varieties, crop diversification and intensification, efficient use of farm inputs, agronomic practices, stable economic return, to ecosystem services management. The functional production systems become more important than single commodity production systems. Recent advances in Earth Observation System (EOS), Open-Access (AO), Artificial Intelligence (AI), Machine Learning (ML), Information, and Communication Technologies (ICTs), Cloud Computing Platforms (CCP) along with smartphone-enabled Citizen Science (CS) increasingly make Big-Data analytics much smarter, interoperable and much useful than ever before, and create valuable baseline information for decision making. This has opened tremendous opportunities to address the knowledge gaps at multiple levels (e.g., data, yield, ecology, economy, resilience) for demand-driven ecological interventions across the scale (e.g., space, time and package). Ongoing efforts in big-data driven digital augmentation aim at quantifying functional production dynamics and drivers to target sitespecific sustainable developmental interventions and scaling the ecological intensification such as intensification of pulses in cerealbased systems (rice fallows), adoption of conservation agriculture, bridging the yield gaps, geo-localization of the research and impact reporting. Here we present some of the ongoing efforts in EOS Big Data for digital augmentation for accelerating agroecological intensification in different agroecologies and regions in the drylands.
\end{abstract}

\section{INTRODUCTION}

Drylands host an enormous variety of biophysical environments with extremely contrasting socio-economic and demographic conditions. This complexity leads to a wide variability in agricultural functions and productivity across spatio-temporal scales. Therefore, there is a definite need for an ecosystembased approach (Gaba et al., 2015) for better managing natural resources to improve productivity in a sustainable way that integrates three main goals - environmental health improvement, economic profitability, and social equity. Enormous efforts are underway to gather geotagged data and information on agricultural production and related aspects at various scales (http://bigdata.cgiar.org/). Plenty of the research knowledge available for the increasing mono-crop productivity but without much emphasis on the ecological functions of the productivity. Another limitation is the availability of real-time (quasi) data and information, which was hardly addressed yet. There is a need for real-time analytics that also feed to metaanalysis for diffusion of ecological functions for designing demand- driven, site-specific decision making and policy implementation for sustainable agroecosystems in the dry areas. The resultant analytics may also help addressing three key factors- increasing yield, reducing inputs cost and price parity towards increasing farmers' income and making farming a base for sustainable jobs and livelihoods.
Machine learning (ML) techniques in combination with big data in cloud processing platforms create new opportunities to analyse the data (e.g., agrometeorological, socioeconomic, and supply-demand data). ML algorithms consist of a learning process (through "prior experience" or "prior knowledge" called training dataset, which could come from in-situ measurements or other statistical data bases) to execute the assigned task. The success of the ML algorithms depends on the volume of the training datasets, learning type (e.g., supervised and unsupervised) and learning models (e.g., clustering, dimensionality reduction, etc.). The applications of ML in agriculture includes crops/species recognition (e.g., crop type mapping), yield estimation and prediction, pest and disease identification, crop health monitoring in real-time and many more (Liakos et al., 2018). Therefore, earth observation systems (EOS) together with ML, Big Data, Cloud Computing Platform (CCP) can be considered a powerful set of tools which can extract information out of raw data and provide meaningful insights in real-time, which influences investment (governments and donors), farmers, researchers and market value chain. Billions square of geospatial data acquired from different platforms (satellite, aeroplane, UAV and terrestrial scanner) and geotagged farm information can be put to use with the Big Data ecosystem to give infinite answers and insights of the agricultural operations across the scale (e.g., space, time and

\footnotetext{
* Corresponding author
} 
package). The information is produced in the form of maps, statistics or both. Stakeholders (both decision makers and farmers) can access the information and run the queries from anywhere at any time with great speed, accuracy and clarity.

\section{APPROACH}

The drylands represent wide agroecologies with complex production systems from highly intensive irrigation to rainfed and agropastoral systems. The most intensive crop production occurs in the drylands with intensive irrigation (Xiao et al., 2006; Biradar et al., 2009; Thenkabail et al., 2009). Since the green revolution, the yield has been a single major focus than functional systems resulted in loss of agrobiodiversity, nutrition and soil health in the farming systems (De Frature et al., 2010; Tilman and Clark, 2014; Kemp, 2016) and it was adopted mostly well-endowed regions like North Western part of India. The production follows function and functional agricultural systems are vastly more productive and sustainable than dysfunctional systems such as single-cropping or few key crops over the long term. This requires dramatic transformational changes from mono-cropping systems to multi-cropping systems and re-design of the present agricultural landscape with functional metrics (Dwivedi et al., 2017; Biradar et al., 2019). This entails the systematic quantification of the agricultural production systems and agro-tagging at multiple scale(s) with a wide array of data sources to design sound agroecology-based innovative strategies that are both sustained by nature and sustainable in their nature (Tittonell, 2014). The effective use of integrated data in geospatial domains helps to develop ecological-intensification to design eco-zones with locationspecific crops/varieties, crop sequence, rotation, intensity and crop water productivity (Biradar et al., 2009, Low et al., 2017) under variable and uncertain climate. Such ecologically balanced agricultural production systems (agroecosystems) contributes to the UN's Sustainable Development Goals (SDGs).

\section{USE CASES}

Several ongoing efforts by leveraging the big-data analytics to build use-cases to quantify the agricultural dynamics, understand the variability and drivers for sustainable production systems. Project-based site-specific studies have under been taken in different agroecologies across the dry areas (http://geoagro.icarda.org/); such as intensification of food legumes in rice fallows in South Asia, adoption of conservation agriculture practices in North Africa, quantification of yield gaps and land degradation in central Asia (Zhang et al., 2017; Low et al., 2018;), transboundary land/water productivity at river basins (Biradar et al., 2017). Here we present one use-case on 'sustainable intensification of the rice fallows' in India as an example and other use-cases can be found in the dedicated portal (http://geoagro.icarda.org).

\subsection{Sustainable intensification of rice fallows}

As food and nutrition increases with increase in population the supply-demand gap continues to rise, the total arable land area is not expected to increase significantly, and future increase of agricultural production will depend more upon sustainable intensification of crop fallows. Agricultural fallow areas offer an excellent opportunity for growing additional food and nutrition if their production potential can be unlocked addressing some of the constraints. One such intensification opportunity lies in the use of rice fallows. At present, nearly $\sim 11$ million hectares of rice-fallows are left unutilized. Untapping the potential use of these fallows may help in bridging the productivity as well as nutrition gaps in eastern India which is yet to be achieved (Sahoo et.al., 2014; Dwivedi, 2017). Such large-scale agricultural intensification needs up-todate information on the dynamics of the rice-based production systems, farm typology, crop and variety specific suitable areas, natural resource base and value chains. Such requirement has led to the development of digital agricultural platform designed to help intensification and crop diversification in crop fallows with food legumes. The digital interactive platform help analyse the farming systems, patterns, dynamics of the crop fallows, length of fallows duration, the start and end of the fallow periods, their seasonality, cropping intensity, etc. helping targeting sustainable intensification of the legumes crops in the rice fallows with multiple benefits to farmers as well the environment.

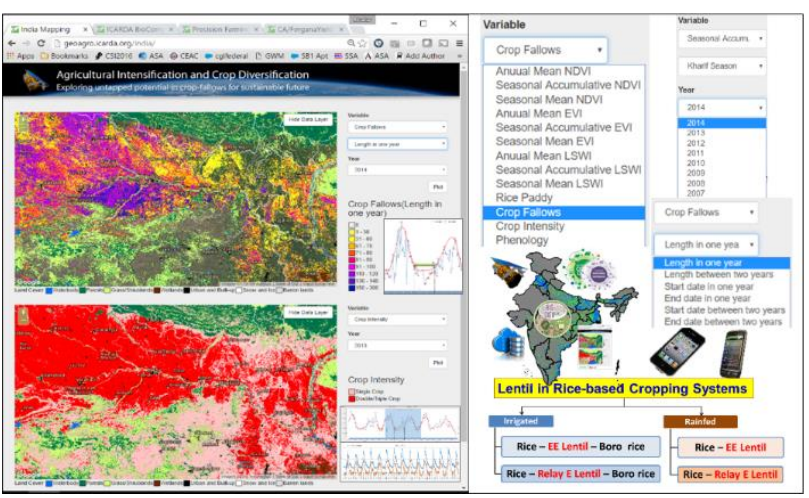

Fig. 1. Spatial Big-data based digital agricultural platform for ecological intensification of rice fallows in India (http://geoagro.icarda.org)

Smallholder agriculture applications (with typical land parcel size $<2 \mathrm{ha}$ ) requires very fine spatial resolution data to map the rice fallow areas for pulse intensification towards conservation agriculture practices and economic growth of the smallholder and marginalized farmers. Copernicus Sentinel-series satellite mission provides high spatial and temporal resolution data at $10 \mathrm{~m}$ at a frequent time interval (3-5 days' revisit period) multifaced opportunities to assess and monitor the small agri-land parcels for sustainable agricultural practices, specifically pulse intensification in rice fallow areas. However, agrarian mapping using high-resolution satellite data remains a challenge in India (e.g., West Bengal) because of heterogeneity and fragmentation of the landscape as well as complex crop cycles. Smallholding agricultural land and diversify cropping pattern are not only puzzling to map the rice fallow area. The real challenge lies in how to process and analyse all the data so that real-time rice fallow areas can be mapped to take rapid decisions. Processing and analysing multisource remotely sensed data (top soil moisture, precipitation, temperature, etc.) at a high spatiotemporal scale resolution is a major constraint for both computer storage and operating capacity. The cloud-based processing in conjunction with machine learning algorithms is a viable option to reduce the load of sophisticated hardware and software requirements at the user end. Google Earth Engine (GEE) is such a cloud-based platform for large-scale geospatial data analysis. The extent, distribution and characteristics (e.g., irrigation versus rainfed, cropping intensity) of rice fallow are factors which are needed to know for pulse intensification in the state. For this purpose, decadal dynamics of land use was 
assessed by mapping rice fallows in the period 2000 to 2018 , based on an automated automated workflow using MODIS at Gangetic plains (from 2000 onwards) and Sentinel 2 satellite imagery (from 2015-2018) in GEE platform. This provide insights into the impact of monsoon dynamics associated rice fallows.

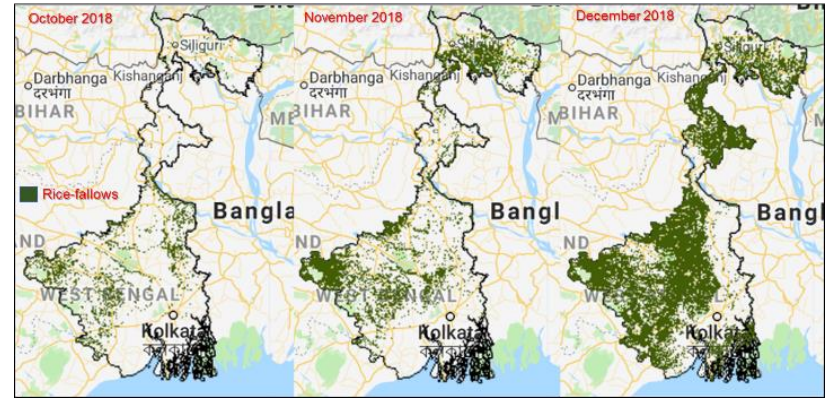

Fig. 2. Mapping real-time rice-fallows in 2018 for supporting pre-planting decision making for pulse intensification in the state of West Bengal, India.

\section{RESTORING AGROECOSYSTEMS}

Loss of farming system diversity, coupled with soil degradation and water scarcity remain key factors for determining sustainable agricultural productivity and the future of the agri-food systems. Agriculture production at present is solely relying on few crops predominantly under monocultures of industrial agriculture. However there exist still many traditional farming systems with a wide array of practices and production functions support the resilience of agroecosystems (Altieri et al., 2015; Mehta, 2017; Biradar et al., 2019). The diversified agroecosystems are found to be more productive, help in bridging the yield gaps, more sustainable and resilient to extreme climate events (Astier, et al., 2012 Gaba et al., 2015; Löw et al., 2018). A regular, accurate and costeffective spatial monitoring of rice-based production systems with satellite data made feasible for target specific legume intensification. It provides spatially explicit information retrieval about crop productivity, pattern, inter and intraseasonal as well as farm variability which help developed an integrate agroecosystems. One of the major constraints of rice fallows is related to soil and water management. With help of geospatial tools and using water balance studies, site specific crop planning can be suggested based on available soil moisture and crop water requirement of suitable pulse crops (Sahoo et al., 2014 and Bandyopadhyay et al, 2015; Biradar et al., 2019) Such principles need to be embedded in various farm practices and agricultural development strategies, where each one has different effects on productivity, stability and resiliency within the farm system. The digital technology would play a key role in the effective diffusion of sustainable agroecosystems and targeting wider and faster adoption to changing climate and demography. Finally, only by creating policies endorsed diffusion of digital technology that integrates ecological functions with economic and social welfare promote the adoption of sustainable agricultural systems across the scales.

\section{CONCLUSIONS}

Digital augmentation in agriculture through Big Data analytics not only helps to understand the relation between climatic drivers, farm inputs, environmental status, productivity and market value chain but also supports to increase farm efficiency in terms of agroecology and economy. The core functionalities of digital intervention in building inclusive agroecosystems involves (i) Sensing mechanism (both in-situ and/or remote observation, such as satellites) and real-time (or offline) mapping and monitoring, (ii) Analysis and re-analysis of multisources data at different scales, (iii) Decision making framework providing timely information at multiple scale and uses, (iv) Targeting (site-specific) interventions and implementation and (v) most importantly providing online platform for stakeholders. Farmers have always been facing challenges of crop failure due to ever-changing weather, pest and disease, havoc crop loss for natural disasters and many more. Cutting edge technological intervention with big data analytics is helping to protect the existing crop at the field and suggesting suitable crop during fallows considering site-specific soil health, farm typology, water availability, climatic/weather condition and market value chain, which further ensure to increase productivity and agroecosystem valuation in a sustainable way. GeoAgro based digital augmentation framework by ICARDA provides data and products that that help build resilient agroecosystems and livelihoods security.

\section{ACKNOWLEDGEMENTS}

We also acknowledge funding from the government of India (ICAR). We also thank the IFAD and Governments of the West Bengal and Odisha for supporting field trips and also thank field team and partners. We also acknowledge Google Earth Engine and NASA/USGS/Copernicus for providing free computational power and satellite images.

\section{REFERENCES}

Altieri, M., Nicholls, C., Henao, A., Lana, M.: Agroecology and the design of climate change-resilient farming systems. Agron. Sustain. Dev. 35:869-890 (2015)

Astier, M, García, L., Galván, Y., González, E., Masera, R.: Assesing the sustainability of small-farmer natural resource management systems. A critical analysis of the MESMIS program (1995-2010). Ecol Soc 17(3):25 (2012)

Bandyopadhyay, K.K., Sahoo, R.N., Singh R., Pradhan, S., Krishna, G., Pargal, S., and Mahapatra, S K. 2015.Characterization and crop planning of rabi fallows using remote sensing and GIS 108, 2015 Current Science 108 (11): 2051-2062

Biradar C. et al. 2019. Digital Diffusion for Inclusive Agroecosystems. In: Chenchouni H., Errami E., Rocha F., Sabato L. (eds) Exploring the Nexus of Geoecology, Geography, Geoarcheology and Geotourism: Advances and Applications for Sustainable Development in Environmental Sciences and Agroforestry Research. Advances in Science, Technology \& Innovation (IEREK Interdisciplinary Series for Sustainable Development). Springer, Cham

Biradar, C.M., Thenkabail, P.S., Noojipady, P., Yuanjie, L., Dheeravath, V., Velpuri, M., Turral, H., Gumma, M.K., Reddy, O.G.P., Xueliang, L. C., Xiao, X., Schull, M.A., Alankara, R.D., Gunasinghe, S., Mohideen, S.: A global map of rainfed cropland areas (GMRCA) at the end of last millennium using remote sensing. International Journal of Applied Earth Observation and Geoinformation, 11 (2), 114-129 (2009)

De Fraiture, C., Molde, D., Wichelns, D. 2010. Investing in water for food, ecosystems, and livelihood: an overview of the 
comprehensive assessment of water management in agriculture. Agriculture Water Management. 97,495-501

Dwivedi, S.L., Lammerts van Bueren, E.T., Ceccarelli, S., Grando, S., Upadhyaya, H.D., Ortiz, R., 2017. Diversifying Food Systems in the Pursuit of Sustainable Food Production and Healthy Diets. Trends in Plant Science. 22(10), 842-856

Gaba, S., Lescourret, F., Boudsocq, S. Enjalbert, J., Hinsinger, P., Journet, E., Navas, M., Wery, J., Louarn, G., Malézieux, E., Pelzer, E., Prudent, P., Lafontaineet, H.: Multiple cropping systems as drivers for providing multiple ecosystem services: from concepts to design. Agron. Sustain. Dev. 35 (2), 607-623 (2015)

GeoAgro Homepage, http://geoagro.icarda.org/ (last accessed 2018/05/14).

Kemp,C.2016. Losing our taste for diversity. Science. 351,567

Liakos, K., Busato, P., Moshou, D., Pearson, S. and Bochtis, D., 2018. Machine learning in agriculture: A review. Sensors, 18(8), p.2674.

Low, F., Biradar, C., Dubovyk, O., Fliemann, E., Akramkhanov, A., Vallejo, A. N. and Waldner, F.: Regionalscale monitoring of cropland intensity and productivity with multi-source satellite image time series. GIScience \& Remote Sensing, 55 (18), 539-567 (2018).

Mehta, M.H.: Eco Agri Revolution: Practical Lessons and The Way Ahead. New India Publishing Agency- Nipa, New Delhi, India (2017)

Sahoo, R.N., Bandyopadhyay, K.K., Pradhan, S., Singh, R., Singh, S. and Krishna, G. 2014. Characterization and Crop Planning of rabi fallows using Remote Sensing and GIS - A Key Component for Bringing Green Revolution in Eastern India. Division of Agricultural Physics, Indian Agricultural Research Institute, New Delhi- 110 012, India. pp.65. TBICN:130/2014

Tilman, D. and Clark, M. 2014. Global diets link environmental sustainability and human health. Nature 515, 518-522

Tittonell, P.A. 2014. Ecological intensification of agriculture sustainable by nature. Current Opinion in Environmental Sustainability 2014, 8:53-61.

Zhang, G., Biradar, C., Xiao, X., Dong, J., Zhou, Y., Qin, Y., Zhang, M., Thomas, R. 2017. Exacerbated grassland degradation and desertification in Central Asia during 20002014. Ecological Applications. EAP17-0074. 